\title{
Effects of Temperature and Wetness Duration on the Sporulation Rate of Phomopsis viticola on Infected Grape Canes
}

\author{
D. J. Anco, L. V. Madden, and M. A. Ellis, The Ohio State University, Department of Plant Pathology, Ohio Agricultural Research and \\ Development Center, 1680 Madison Avenue, Wooster, Ohio 44691
}

\begin{abstract}
Anco, D. J., Madden, L. V., and Ellis, M. A. 2013. Effects of temperature and wetness duration on the sporulation rate of Phomopsis viticola on infected grape canes. Plant Dis. 97:579-589.

Controlled-environment studies were conducted to examine effects of temperature $(T)$ and wetness duration $(W)$ on the sporulation rate of Phomopsis viticola on infected grape canes and to determine effects of interrupted wetness duration (IWD) on sporulation. A split-plot design was used to determine $T$ and $W$ effects, with $T(5,12,15,18,20,22$, 25,28 , and $\left.35^{\circ} \mathrm{C}\right)$ as the whole-plot and $W(11,23,35,47$, and $71 \mathrm{~h})$ as the subplot. Linear and nonlinear mixed models were fitted to the data. Lower and upper limits of sporulation were estimated to be 4 and $36^{\circ} \mathrm{C}$, respectively, based on the modeling results, optimum sporulation was near $21^{\circ} \mathrm{C}$, and sporulation increased monotonically with increasing wetness duration. Of the examined models, a generalization of the Analytis Beta model fit the data best, based on a collection of goodness-of-fit statistical criteria. To determine effects of IWD, a split-plot was used, with $T\left(12,15\right.$, and $\left.20^{\circ} \mathrm{C}\right)$ as the whole-plot and $\operatorname{IWD}(0,2$,

$4,8,12$, and $24 \mathrm{~h}$ ) as the subplot. Generally, sporulation declined with increasing IWD. An IWD of $8 \mathrm{~h}$ or more resulted in significantly and substantially less sporulation compared to the control $(0$ h IWD $)(P<$ $0.01)$. Temporal patterns of spore density in the field were determined using a repeated-measures design, in which spore density and environmental data were measured in the vineyard during and following individual rain events over 3 years. The developed model from the controlled-environment study, coupled with a time-of-season weight function and a dispersal index (based on total rain per rain episode), predicted the trend in spore density over time reasonably well, although the total magnitude of spore density could not be predicted because the density of lesions was not known. Results can be used for improving the accuracy of a disease warning system that currently only considers infection of grapes by $P$. viticola.
\end{abstract}

Despite fairly extensive fungicide programs, the incidence of Phomopsis cane and leaf spot (PCLS) appears to be increasing in many Ohio vineyards. This disease, caused by Phomopsis viticola (Sacc.) Sacc., occurs on Vitis spp. worldwide but becomes most economically important in temperate regions (17). Under conditions favorable for disease development, PCLS has been reported to reduce yields by up to $30 \%(7,12)$. Although PCLS is capable of affecting all aboveground tissues of grape at some stage in their development, it has its greatest impact on yield when affecting fruit and rachises, which are susceptible throughout their development (11). Recent research has been published describing variation and spatial patterns of disease incidence of PCLS $(29,30)$, as well as the effects of environmental factors (temperature and wetness duration) on infection of grape canes and leaves by $P$. viticola $(12,31)$. Furthermore, we have recently shown that $P$. viticola has the potential to sporulate on canes and rachises from bud break through bloom the year following infection (3). The relationship of (relative) sporulation potential with day of year is described well by a bell-shaped curve (3). Despite these recent advances in our knowledge of the epidemiology of PCLS, there have been no reports on the effects of environmental factors on the development of primary inoculum (sporulation) of $P$. viticola in the field. This is an extremely important component of the disease. Under environmental conditions that are not favorable or do not allow for sporulation, fungicide applications for disease control are not required, even if

Corresponding author: M. A. Ellis, E-mail: ellis.7@ osu.edu

Accepted for publication 18 October 2012.

http://dx.doi.org/10.1094/PDIS-07-12-0666-RE

(C) 2013 The American Phytopathological Society conditions for infection are favorable during the time of year when sporulation can occur (3). Understanding the environmental factors that affect sporulation may be beneficial in controlling the disease, through improving the timing of fungicide applications or eliminating unneeded fungicide applications. Improving chemical control of this disease is important because, while cultivars may vary in their susceptibility to PCLS, resistant cultivars are currently not available $(7,17)$.

In 2008, research was initiated to determine the environmental factors (temperature and wetness duration) required for primary inoculum production (sporulation) of $P$. viticola in the field. These studies will be helpful in predicting the timing and amount of sporulation of $P$. viticola. Our first objective was to examine the effects of combinations of temperatures and wetness durations on the sporulation rate of $P$. viticola on infected grape canes and to use the collected data to develop a model for sporulation. Our second objective was to determine the effects of interrupted wetness duration (split wetness periods) on sporulation of $P$. viticola. Finally, our third objective was to measure spore density and environmental variables in the vineyard in order to determine if predictions from the model developed under the first objective were consistent with observations in the field, and to develop a protocol for predicting relative spore density following wetness events in the field. Preliminary results based on a subset of the entire multiyear data set for the third objective have been presented in symposium proceedings (2).

\section{Materials and Methods}

Effects of temperature and wetness duration on sporulation. Sporulation per unit area of infected grape cane was determined for five wetness durations at each of nine temperatures. Infected canes were obtained from inoculated shoots in a vineyard, and sporulation rate was determined under controlled conditions in growth 
chambers. Experimental design was a split-plot with temperature $\left(5,12,15,18,20,22,25,28\right.$, and $\left.35^{\circ} \mathrm{C}\right)$ as the whole-plot and wetness duration $(11,23,35,47$, and $71 \mathrm{~h})$ as the subplot. Three experimental repetitions were realized over 2009, 2010, and 2011, each with two blocks, using material collected before the growing season each year.

The 'Catawba' vineyard ( $\mathrm{N} \mathrm{40} 45.839^{\prime}$, W 81 ${ }^{\circ} 54.672^{\prime}$ ) used in these studies was located at Snyder Farm at the Ohio Agricultural Research and Development Center (OARDC), Wooster, OH. Vines were $2.1 \mathrm{~m}$ apart, and rows were $3 \mathrm{~m}$ apart. The vineyard was planted in 1995, and 1-year-old canes were trained in position according to an umbrella Kniffin system. For each year following the initiation of these studies, remaining 1-year-old infected canes were spur pruned, and when present, rachises were allowed to remain in the canopy. This vineyard had not received fungicide applications for PCLS for 4 years and has high levels of naturally occurring PCLS infections. In addition, the five most easterly rows (12 vines/row) were inoculated with $10^{7} \alpha$-conidia $\mathrm{ml}^{-1}$ of $P$. viticola wild type strain $\mathrm{OH}-22$ (44) by spraying young shoots until runoff with a handheld, 11-liter Challenger VI sprayer (Spartanburg Steel Products, Inc., Spartanburg, SC). Details on inoculum production are in Anco et al. (3). In 2008, 2009, and 2010, shoots between Eichhorn-Lorenz stage (EL) 09 and 12 (2 to 3 leaves unfolded and inflorescences visible, respectively) were inoculated on 7 May, 8 May, and 11 May, respectively (10). After each inoculation, overhead irrigation was utilized to supplement natural rainfall to ensure sufficient wetness duration at encountered temperatures to produce an infection event with at least low predicted infection according to the warning system developed by Nita et al. (31).

To avoid potential variation in sporulation from collecting canes on multiple sampling dates, all canes $(\sim 1,900)$ used in the first two objectives were collected on one sampling date each year. This sampling date was typically in mid-March before bud break and was based on the potential for $P$. viticola to consistently sporulate on infected canes after $48 \mathrm{~h}$ incubation in sealed moist chambers at $23^{\circ} \mathrm{C}(3)$. After sampling, canes were immediately placed inside four layers of $0.0508 \mathrm{~mm}$ ( $2 \mathrm{mil}$ ) clear polyethylene bags (i.e., a bag within three other bags), and each bag was separately sealed with a twist tie. Samples were stored in a $-20^{\circ} \mathrm{C}$ freezer. Canes were randomly removed from the freezer in groups of 75 (5 wetness durations per temperature, 15 canes per temperature-wetness duration combination), allowed to thaw, and surface-disinfested. Cane samples $(\sim 10 \mathrm{~cm}$ long) were surface-disinfested by soaking for $5 \mathrm{~s}$ in $70 \%$ ethanol, then $1 \mathrm{~min}$ in $0.5 \%$ sodium hypochlorite, and then rinsing under deionized water for $2 \mathrm{~min}$. After surface disinfestation, canes were placed in moist chambers $(22 \times 22 \times 10$ $\mathrm{cm}$ plastic containers) with 3.64 liters of deionized water in the bottom. Metal screens were bent to hold canes above the deionized water and below the plastic top. When sealed with clear polyethylene, the dew point was reached at all temperatures investigated. This resulted in relative humidity at $100 \%$ and a visible layer of free water on the canes. The transparent polyethylene allowed light to penetrate. Moist chambers were randomly arranged in the center of a model 57 growth chamber (Controlled Environments Inc., Pembina, ND). The growth chamber was lit with fluorescent lights on a 16:8 h photoperiod with a photosynthetically active radiation output of $57 \mu \mathrm{E} \cdot \mathrm{m}^{-2} \cdot \mathrm{s}^{-1}$ (Apogee Quantum Meter model LQS-QM, Logan, UT) at the cane level. Moist chambers were randomly removed from the growth chamber at $11,23,35,47$, and $71 \mathrm{~h}$, after which sporulation was quantified.

Canes were vortexed in $20 \mathrm{ml}$ deionized water in $25 \times 150 \mathrm{~mm}$ test tubes for $10 \mathrm{~s}$ using a Vortex Genie 2 set at vortex speed 5 (Fisher Scientific, Pittsburgh, PA). Sporulation on each cane was quantified as the average of six hemacytometer readings (providing a lower conidial concentration detection limit of $\sim 1.67 \times 10^{3}$ per $\mathrm{ml}$ ), from which the number of conidia per 20-ml suspension and per $\mathrm{mm}^{2}$ sample surface area was calculated. Surface area was estimated assuming a surface area $(S)$ given by a cylinder, in which $S=2 \times \pi \times r \times h$, where $r$ is the radius and $h$ is the length of the cane. When cane samples had multiple internodes, surface area was estimated separately for each internode and summed. Temperature and wetness duration were monitored in 5-min intervals with a WatchDog model 130 logger (Spectrum Technologies, Inc., Plainfield, IL). The order of different temperatures was random in each repetition of the experiment.

Data analysis for temperature and wetness duration effects. Linear and nonlinear mixed-model regression analyses were used to develop a model for sporulation rate in relation to temperature and wetness duration. The REG, NLIN, and NLMIXED procedures of SAS 9.2 (SAS Institute Inc., Cary, NC) were used for all analyses. Linear models were of the polynomial form (42), and nonlinear models were generalizations of the Analytis Beta model (1) and a Weibull function $(8,49)$. Data from the three repetitions were pooled and analyzed in PROC NLMIXED. To stabilize variances, sporulation was transformed to $y=\log _{10}\left(\alpha\right.$-conidia $\left./ \mathrm{mm}^{2}+1\right)$.

The sporulation rate statistical model can be written as:

$y=f(T, W)+r+e$

where $T$ is temperature $\left({ }^{\circ} \mathrm{C}\right), W$ is wetness duration (hours), $f(T, W)$ is the linear or nonlinear (deterministic) function of $T$ and $W, r$ is the random effect of repetition, with a normal distribution with mean 0 and variance $s_{r}^{2}$, and $e$ is the residual error (with mean 0 and variance $s_{e}{ }^{2}$ ). For convenience, subscripts are suppressed. The polynomial model can be written as:

$f(T, W)=b_{1} W+b_{2} W T+b_{3} W T^{2}=W\left(b_{1}+b_{2} T+b_{3} T^{2}\right)$

in which $b_{1}, b_{2}$, and $b_{3}$ are parameters. Different combinations of variables were considered for inclusion in the polynomial model; those that were significant were utilized. The generalized Weibull model is written as:

$f(T, W)=f(T) \cdot\left(1-\exp \left\{-[\zeta(W-\eta)]^{\theta}\right\}\right)$

with

$f(T)=\left\{\xi[(\psi+1) / \psi] \psi^{1 /(\psi+1)}\right\}\{\exp [(T-\varsigma) \varphi /(\psi+1)]\} /\{1+$ $\exp [(T-\varsigma) \varphi]\}$,

in which $\zeta$ is the rate parameter of sporulation increase with increasing $W, \eta$ is a lag parameter (hours of $W$ when $f(T, W)=0$ ), $\theta$ is a unitless shape parameter (in part, reflecting the portion of $W$ when the rate of increase in $y$ [acceleration] declines), $\xi$ is the sporulation asymptote at optimum $T, \psi$ is a unitless shape parameter describing the response of sporulation near the optimum $T, \varsigma$ is a parameter proportional to optimum $T\left(\right.$ where $\left.T_{o p t}=\varsigma-[1 / \varphi] \cdot \ln [\psi]\right)$ (in part, the horizontal position of the predicted response curve when sporulation is plotted against $T$ ), and $\varphi$ is the rate parameter of sporulation decrease from its optimum as $T$ increases above, and decreases below, the optimum $T$.

The generalized beta model is written as:

$f(T, W)=\alpha t^{\beta}(1-t)^{\gamma} W^{\delta}$

in which $\alpha$ is the upper sporulation asymptote parameter for sporulation, $\beta$ is a rate parameter of sporulation increase toward its optimum with increasing temperature, $\gamma$ is a rate parameter of sporulation decrease from its optimum with increasing temperature, and $\delta$ is a rate parameter of sporulation increase with increasing wetness duration. The variable $t$ is a scaled temperature measurement, $t=\left(T-T_{\min }\right) /\left(T_{\max }-T_{\min }\right)$, in which $T_{\min }$ and $T_{\max }$ are, respectively, the minimum and maximum temperatures for sporulation.

Unlike the case for linear models, for nonlinear models, the sampling distribution of the parameter estimates can be complex (and non-normal) and highly skewed, with biased estimates, high asymptotic standard errors, and correlations of the different estimates. The particular parameterization of the model can also have a large effect on achieving convergence in the iterative model-fitting process $(37,42)$. As recommended by Ratkowsky (37) and Schabenberger and Pierce (42), we thus used expected value parameterization for two of the parameters in model fitting to minimize these problems. This approach is described in the Appendix. 
Model appropriateness and goodness-of-fit to the data were assessed using residuals, outlier diagnostics, pseudo- $R^{2}$, concordance correlation coefficient $\left(\rho_{C}\right)(27,28)$, Akaike's Information Criterion (AIC), Hougaard's skewness $(19,20,37,42)$, and correlation of parameter estimates. Residuals were examined by plotting them against temperature and wetness duration. Outlier diagnostic plots were examined using ODS graphics in SAS. With nonlinear models, and with mixed models in general, the usual $R^{2}$ statistic is not applicable, but there are statistics such as pseudo- $R^{2}$ and Lin's concordance coefficient $\rho_{C}$ that have similar interpretations. Pseudo- $R^{2}$ was obtained by regressing predicted against observed $y$ values. The chosen best model was utilized under the third objective to predict relative levels of sporulation in the field.

Effect of interrupted wetness duration on sporulation. The influence of an interruption of wetness duration on sporulation was determined in a controlled environment study. Experimental design was a split-plot, with temperature $\left(12,15\right.$, and $\left.20^{\circ} \mathrm{C}\right)$ as the wholeplot and length of interrupted wetness duration (IWD: 0, 2, 4, 8, 12 , and $24 \mathrm{~h}$ ) as the subplot. Two experimental repetitions were conducted with two blocks each. Infected canes were collected from the vineyard with the inoculated plants, stored, surface disinfested, and incubated as previously described. The chosen temperatures were based on the commonly encountered range of temperatures in the field during wetness events in the spring (M. A. Ellis, unpublished).

After the initial wetness duration of $24 \mathrm{~h}$, metal screens that supported the canes were removed from the moist chambers and placed on top of the resealed moist chambers. The canes typically dried in less than $5 \mathrm{~min}$ based on visual observations. Allowing the chambers to remain in the controlled environmental chamber resulted in a consistent temperature during the wetness interruption. The positive control consisted of $0 \mathrm{~h}$ IWD, during which the canes remained in the moist chamber and did not dry. After each IWD, canes and metal screens were rewetted with deionized water sprayed from a model 5KH33DN16AX atomizer (pressure: $\sim 55$ $\mathrm{kPa}$, distance: $\sim 19 \mathrm{~cm}$ ) (General Electric, Fairfield, CT) to the point just before runoff and placed back inside their respective moist chambers for a final wetness duration of $24 \mathrm{~h}$. Sporulation was quantified as previously described.

Data analysis for interrupted wetness duration. In order to determine whether the effect of IWD depends upon $T$, a generalized linear mixed model (GLMM) was fitted to the data using the GLIMMIX procedure of SAS. It was assumed that spores per unit infected area had a Poisson distribution with mean $\mu$; the log link function of $\mu$ was modeled as a function of the experimental factors. Fixed-effects factors in the model were IWD, $T$, and the interaction of IWD and $T$ (i.e., IWD $T$ ). Random effects in the model included repetition, the whole plot error term, and the residual error term. One-sided contrasts of least squares means were used to determine which IWD resulted in a significantly reduced sporulation rate compared to the control ( 0 IWD). The Monte Carlo simulation method (9) was used to adjust $P$ values for multiple comparisons of the estimated means for the different IWD levels. For further evidence of IWD effects, isotonic contrasts (18) were conducted to determine when the rate of sporulation monotonically decreases compared to the average sporulation rate of previous IWD levels.

Spore density in the field following rain events. Rain-splash dispersed spores were sampled following rain events in a vineyard over each of 3 years. This investigation utilized a repeatedmeasures experimental design. Three experimental repetitions were conducted from 2009 to 2011.

Fifteen spore traps were randomly placed next to the main trunks of grapevines, three traps per row, in the five most easterly (previously inoculated) rows of the Catawba vineyard. Spore traps were similar to those used by Nita et al. (31), and they consisted of 2-liter plastic bottles connected to 196-mm Urbanti funnels (CP Lab Safety, Novato, CA) via $2.5-\mathrm{cm}$ inside-diameter Nalgene premium tubing. Upright position of traps was maintained with a combination of metal T-posts, plastic wire, and iron support rings and plates.
Traps were collected after every rain event from at or before grape bud break through bloom until no $P$. viticola spores $(\alpha$-conidia) were observed for three consecutive rain events. A rain event was defined as any period of precipitation after which a quantifiable amount of water was collected in the traps $(0.1 \mathrm{~mm}$ or more). Rain events were considered ended (before analysis of environmental data) if additional rain was not expected within $4 \mathrm{~h}$. After being collected, spore traps were immediately refrigerated before their spores were counted. Water from each trap was magnetically stirred during quantification. Spore density per trap was measured as the average of six hemacytometer readings multiplied by the amount of water collected in each trap. Average spore density per trap was calculated from all 15 traps for each rain event. $P$. viticola spores were identified by morphology and colony characteristics when wash suspensions were occasionally spread on PDA amended with $0.05 \mathrm{~g} \mathrm{liter}^{-1}$ streptomycin sulfate. Plates were incubated as previously described. This process also verified viability of conidia.

Environmental variables were collected every $5 \mathrm{~min}$ with a Campbell Scientific data logger (Campbell Scientific, Logan, UT) adjacent to the Catawba vineyard. Temperature was measured with two shielded Campbell Scientific thermisters (models 107 and CS215), which were placed $1.6 \mathrm{~m}$ aboveground in the canopy. Leaf wetness was measured with two Campbell Scientific model 237 circuit board sensors coated with latex and placed in the canopy $1.7 \mathrm{~m}$ aboveground. Sensor readings less than 1001 on a 0 to 6999 scale were used to indicate surface wetness. The duration of a wetness event was determined from the average of the two wetness sensors for each recording time. Temperature during leaf wetness periods was based on the average measurements from the two thermisters across the recording times. Precipitation was recorded with a model TE 525 tipping bucket rain gauge adjacent to the vineyard $1.8 \mathrm{~m}$ aboveground (Texas Electronics, Dallas, TX).

Data analysis for spore density in the field. The model developed under the first objective was evaluated for its effectiveness in predicting (relative) spore density after each rain event based on corresponding environmental data and observed spore density. A leaf wetness event (LWE) was defined by the presence of leaf wetness (from rain or dew) preceding the end of a rain event; individual LWEs did not necessarily result in predicted sporulation. Rain events often consisted of multiple LWEs separated by varying lengths of IWD, and LWEs were pooled or separated based on the IWD threshold concluded from the second objective $(8 \mathrm{~h})$. The selected nonlinear model developed under the first objective (with parameter estimates also developed in the controlled-environment investigation, and not with the field data) was used to predict spore density based on average temperature during leaf wetness and total hours of wetness duration for the LWE. However, this model was developed based on sporulation occurring on infected canes with a known unit surface area and with lesions of a (mostly) uniform age. Moreover, the sampled spores in the field are only those that were successfully dispersed to the spore samplers by rain splash. Since the spore traps in the field would be sampling from an unknown total surface area of infected tissue, from a distribution of lesion ages, and following rain events with different properties, the developed model would only be able to predict relative amounts of spore density (which we label a sporulation index). Using the previously developed model, a sporulation index per LWE was calculated on a log scale $\left(y_{p}\right)$ and back-transformed to obtain the index on an arithmetic scale (relative number of $\alpha$-conidia; $I_{p}$ ).

One factor to consider in predicting spore density was the aging of the lesions over the season. Anco et al. (3) showed that a bellshaped curve, described by a modified beta model, described the sporulation potential of lesions over the course of a growing season (independent of actual environmental conditions in the field at the time). Thus, $I_{p}$ values were weighted $\left(w_{d}\right)$ according to the day of year on which each LWE ended and summed for all LWEs within each rain event to yield total predicted sporulation index of each rain event. Based on the modified beta model, the weight between 1 March and 2 August is given by: $w_{d}=\left(6.185 \times 10^{5}\right) u^{9.55}(1-u)^{9.89}$, 
where $u=\left(U-U_{\min }\right) /\left(U_{\max }-U_{\min }\right), U=$ day of year, $U_{\min }=1$ March (first day with observed spores), and $U_{\max }=2$ August (day after which no spores were observed). Thus, the day-adjusted sporulation index is given by $I_{d p}=I_{p} \cdot w_{d}$.

This $I_{d p}$ total for a rain event was then weighted with a dispersal index $(D)$ that ranged from 0 to 1 to reflect the fraction of produced spores that would actually be dispersed to the spore sampler during rain events. The dispersal index of each rain event was calculated here strictly based on the total amount of rain (and not other variables) by using the negative exponential equation previously used for rainfall effects on dispersal (39). That is, $D=1-$ $\exp (-V \cdot P)$, where $V$ is a parameter and $P$ is total rainfall $(\mathrm{mm})$ per rain event. The fraction of spores not dispersed by a rain event is 1 $-D$. We label $I_{d p}\left(=I_{p} \cdot w_{d}\right)$ for the predicted spores produced from the most recent wetness events culminating in the current rain and dispersal event as $I_{d p(2)}$, and $D_{(2)}$ for the corresponding dispersal index for the current rain; thus, $D_{(2)} I_{d p(2)}$ represents the predicted (recently) produced spores that are actually dispersed to the samplers. The number of recently produced spores not dispersed in the current rain is $\left(1-D_{(2)}\right) \cdot I_{d p(2)}$. The number of predicted spores produced before the previous rain (labeled with subscript (1)) and not dispersed to the traps by that previous rain is given by $(1-$ $\left.D_{(1)}\right) \cdot I_{d p(1)}$; these spores are available for dispersal in the current rain, at least theoretically (although an unknown fraction would be lost to the system). Thus, the total number of predicted spores caught for the current rain can be written as:

$C_{(2)}=\Omega\left(D_{(2)} \cdot I_{d p(2)}+D_{(2)} \cdot\left(1-D_{(1)}\right) \cdot I_{d p(1)}\right)$

where $\Omega$ is a scaling factor incorporated to equilibrate the scales of observed and predicted relative spore density (accounting for the unknown total number of lesions or area of lesions in the vineyard).

Equation 5 was fitted to the data pooled over years using NLMIXED in SAS, with the addition of a random effect for year $\left(r\right.$, with variance $s_{r}^{2}$ ). It was assumed that observed spores per trap (in millions) had a Poisson distribution. A log link function was used. The only parameters estimated were $\Omega$ and $V$ (with $V$ being the parameter in the dispersal function), because the parameters of the sporulation function (from the first objective) and the daily weight (3) were held fixed (determined from previous studies). Data for rain events prior to bud break with no observed spores and rain events during which the vineyard was inoculated were not included in the analysis.

Model appropriateness and goodness-of-fit to the data were assessed using residuals, outlier and leverage diagnostics, Pseudo- $R^{2}$, and $\rho_{C}$. Residuals were examined by plotting them against predicted spore density. Pseudo- $R^{2}$ was obtained as described previously. Outlier and leverage diagnostic plots were examined using ODS graphics in SAS.

\section{Results}

Effects of temperature and wetness duration on sporulation. Data from 2009, 2010, and 2011 indicated that sporulation of $P$. viticola on infected grape canes can occur between 5 and $35^{\circ} \mathrm{C}$, with an optimum near $21^{\circ} \mathrm{C}$ (Fig. 1). Lower and upper limits of sporulation were predicted to be 4 and $36^{\circ} \mathrm{C}$, respectively. Little to no sporulation was observed at $11 \mathrm{~h}$ wetness duration from 5 to

Table 1. Selected goodness-of-fit statistics for the generalized Beta (equation 4), polynomial (equation 2), and generalized Weibull (equation 3) models fitted to the data from the controlled environment study for temperature and wetness duration effects on sporulation of Phomopsis viticola on grapes

\begin{tabular}{lccc}
\hline Model & ${\text { Pseudo- } \boldsymbol{R}^{\mathbf{2}}}$ & $\boldsymbol{\rho}_{\boldsymbol{C}}^{\mathbf{a}}$ & $\mathbf{A I C}^{\mathbf{b}}$ \\
\hline Beta & 0.89 & 0.89 & 100.6 \\
Polynomial & 0.87 & 0.88 & 113.8 \\
Weibull & 0.89 & 0.89 & 103.6 \\
\hline
\end{tabular}

a Concordance correlation coefficient.

b Akaike's Information Criterion. $35^{\circ} \mathrm{C}$. At durations greater than $11 \mathrm{~h}$, sporulation was observed to clearly increase with increasing wetness duration to the maximum observed wetness duration of $71 \mathrm{~h}$.

All considered models (polynomial, generalized Weibull, and Analytis Beta model; equations 2, 3, and 4, respectively) were successfully fitted to the transformed data, and all three resulted in similar fits to the data (Table 1). Plots of residuals versus wetness duration and temperature for the three models were comparable and did not display obvious (undesirable), major trends (results not shown). Outlier diagnostic plots revealed the presence of seven outliers when equation 2 was fitted to the data; this was less than the number of outliers present when equations 3 and 4 were fitted to the data (both had nine outliers). Outliers were not removed from the dataset since their magnitudes were acceptably small (absolute value less than 3.5), and removal did not result in significantly different parameter estimates (results not shown). Pseudo- $R^{2}$ and $\rho_{C}$ were very similar for the three models, with values for the polynomial model being slightly lower than for the other models, indicating that the polynomial had a slightly poorer fit. The generalized Analytis Beta model's AIC value was more than 2 units lower than for the other models (Table 1), signifying that this model resulted in the best fit based on this information criterion (i.e., AIC combines the likelihood of the data given the model with a penalty for number of parameters [model complexity]). Moreover, the parameter-effects nonlinearity measurements (i.e., Hougaard's skewness) for the beta model parameter estimates were closer to 0 than for the estimated parameters of the generalized Weibull model (Table 2) $(37,42)$ (by definition, this statistic is 0 for linear models [e.g., polynomials]). Correlation of parameter estimates was considerably higher for some pairs of parameters for the polynomial and generalized Weibull models than found for the expected-value parameterization of the Analytis Beta model (Table 3 ). The generalized Beta model was the most appropriate based on all of these results, and parameter estimates and descriptions are in Table 4, with a description of the expected-value parameterization in Appendix 1.

Predicted sporulation increased in a monotonic fashion with wetness duration and had an optimum-type relation with temperature (Fig. 1). There was generally good agreement between observed and predicted sporulation (Fig. 2). The estimated slope parameter (1.003) of the regression equation between observed and predicted sporulation (forced through the origin) was not significantly different from $1(P=0.928, F$ test, REG procedure, SAS $)$.

Table 2. Hougaard's skewness statistic for the parameter estimates of the generalized Beta (equation 4), polynomial (equation 2), and generalized Weibull (equation 3 ) models fitted to the data from the controlled environment study for temperature and wetness duration effects on sporulation of Phomopsis viticola on grapes

\begin{tabular}{lcc}
\hline Model & Parameter & Skewness \\
\hline Beta $^{\mathrm{a}}$ & $\alpha$ & 2.69 \\
& $\gamma$ & 0.28 \\
$\beta$ & 0.30 \\
$\delta$ & 0.20 \\
$S_{1}$ & 0.01 \\
& $S_{2}$ & 0.14 \\
Polynomial & $b_{1}$ & 0 \\
& $b_{2}$ & 0 \\
Weibull & $b_{3}$ & 0 \\
& $\psi$ & 1.54 \\
& $\xi$ & 6.20 \\
& $\varsigma$ & -0.47 \\
& $\varphi$ & 1.10 \\
& $\zeta$ & -2.10 \\
& $\eta$ & -5.83 \\
& $\theta$ & 4.45 \\
\hline
\end{tabular}

a Skewness values for parameters $\alpha$ and $\gamma$ were calculated from the generalized form of the Analytis Beta model, whereas values for $S_{1}$ and $S_{2}$ were calculated from the expected-value parameterization of the generalized Beta model (equation A4). Skewness values for $\beta$ and $\delta$ did not change as a result of the reparameterization. 
Residuals plotted against predicted values exhibited an acceptably random scatter (results not shown).

Effect of interrupted wetness duration. Analysis of data from the two repetitions of the experiment indicated that, as expected, sporulation generally declined with increasing IWD (Fig. 3). While both temperature and IWD were found to be highly significant factors $(P \leq 0.0001)$, the interaction of the two factors was not significant $(P=0.535)$. This lack of interaction can be visualized by the differences of the least squares means (for log link) for the three temperatures changing minimally across the levels of IWD observed in this study on the log scale (the scale of the link function) (Fig. 3). Contrasts of least squares main-effect means for levels of IWD indicated that an IWD of $8 \mathrm{~h}$ or more resulted in significantly and substantially less sporulation compared to the control $(P<0.01)$ (Table 5). The 4-h IWD also showed a less dramatic decrease in sporulation. These results suggest that for field predictions, sporulation should be predicted separately for each wetness period over a threshold IWD of $8 \mathrm{~h}$, and the predictions accumulated, rather than to pool all wetness events for each rain event. Corroborating these results, isotonic contrasts indicated that the monotonic decrease in rate of sporulation (compared to the average of all preceding IWD levels) with increasing IWD first becomes significant after 8 IWD $(P<0.0001$; data not shown $)$.

Spore density in the field following rain events. For 2009, 2010, and 2011, data collected from spore traps indicated that sporulation of $P$. viticola first occurred in the field near bud break (28 April 2009, 8 April 2010, and 26 April 2011) and continued through the end of bloom (20 June 2009, 15 June 2010, and 11 June 2011) (Fig. 4), with the level of spore density in traps varying considerably among the different rain episodes. This corroborates sporulation potential data observed by Anco et al. (3). In 2010 and 2011, spores were sampled from two (22 and 23 March 2010) and eight rain events (from 5 April to 25 April 2011) prior to bud break, respectively. Despite the presence of conditions suitable for sporulation (based on predictions from the model and the presence of rain episodes), spores were not observed in the vineyard prior to bud break (other than in 2011, when a very small number were observed 1 day before $~ 50 \%$ of the buds had opened). These data collection times were omitted from Figure 4. P. viticola was always isolated from collected rain splash when spores identified as $P$. viticola were observed.

Total rainfall per rain event ranged from 0.1 to $60.6 \mathrm{~mm}$. The $V$ parameter of the dispersal index equation was estimated to be $0.0693 \mathrm{~mm}^{-1}(\mathrm{SE}=0.015)$ when equation 5 was fitted to the data. This corresponds to $90 \%$ of produced inoculum being predicted to be dispersed after $\sim 33 \mathrm{~mm}$ rainfall and $99 \%$ of produced inoculum being predicted to be dispersed after $\sim 66 \mathrm{~mm}$ rainfall. The scale parameter $\Omega$ was estimated to be $1.494(\mathrm{SE}=0.126)$. Both $V$ and $\Omega$ parameter estimates exhibited parameter-effects nonlinearity (skewness) values of less than |0.37|; thus, expected-value reparameterization was not conducted for those parameters. Including the random effect of year improved the fit of the model to the data (AIC decreased $~ 17$ units) but did not significantly alter parameter estimates of $V$ and $\Omega$ (confidence intervals from the model with
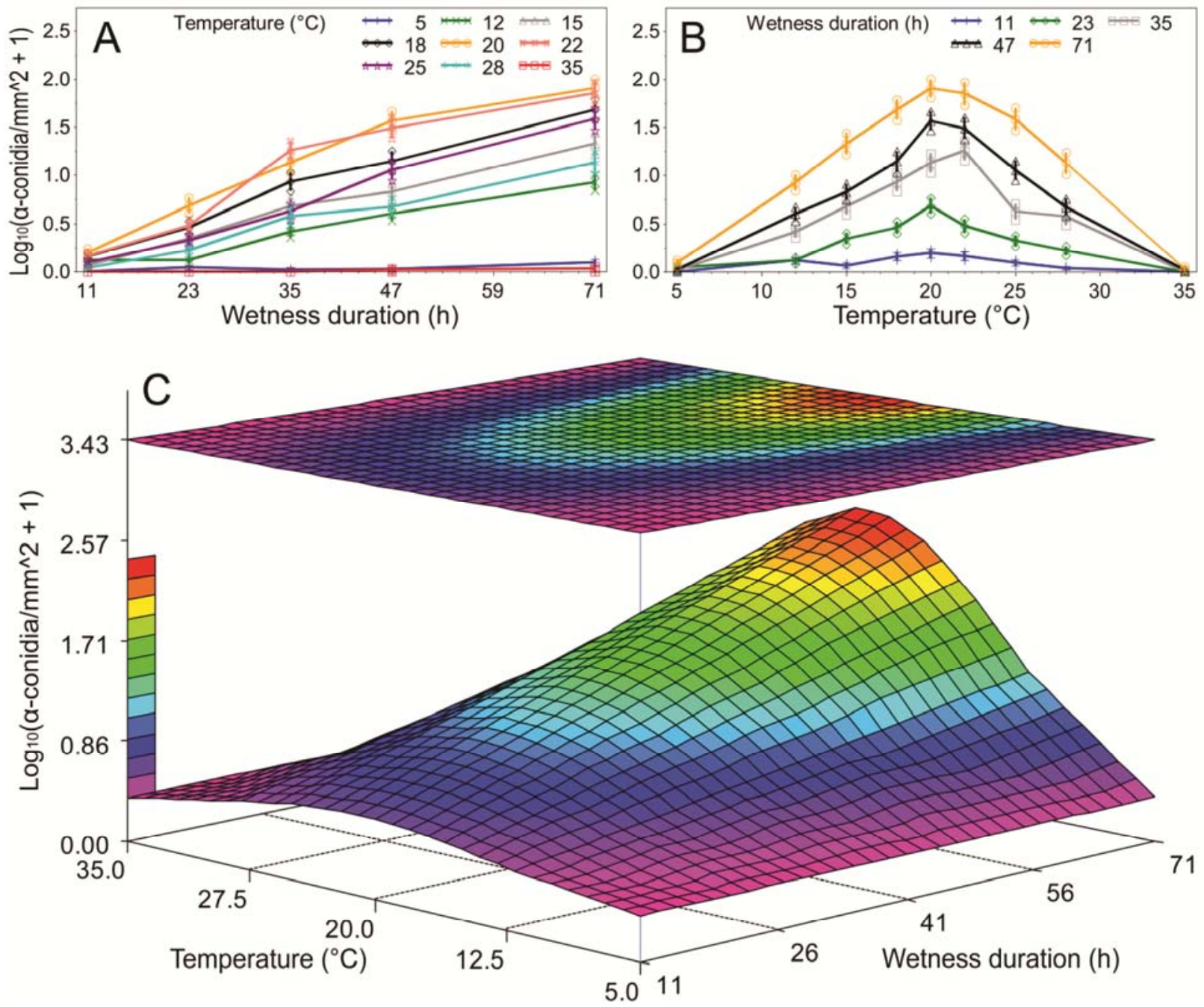

Fig. 1. Observed sporulation of Phomopsis viticola versus A, wetness duration and $\mathbf{B}$, temperature. Error bars are standard errors of the means of three repetitions. $\mathbf{C}$ Predicted effects of temperature and wetness duration on sporulation rate of $P$. viticola on infected grape canes, based on fit of a generalized beta model to the data of the controlled-environment experiments from 2009, 2010, and 2011. 
and without the random effect overlapped). In 2009 and 2011, predicted spore density followed the general trend of observed spore density fairly well. Variability between observed and predicted spore density was slightly greater in 2010 (particularly from 26 April to 6 May and on 31 May) than in 2009 or 2011 (Fig. 4). Around 25 to 26 May 2011, however, there also was some discrepancy, although the trend was consistent for observed and predicted values. At some periods in all years examined, the temporal pattern of predicted spore density varied from that of observed spore density (i.e., predictions increased relative to the immediately previous prediction when observations of spore density decreased relative to the immediately previous observation, and vice-versa).

Generalized nonlinear mixed regression of predicted and observed spore density in the vineyard from 2009 to 2011 indicated that there was a general increase in observed spores as predicted numbers increased (Fig. 5). The estimated slope parameter (0.914) of the regression equation between observed and predicted spore density (forced through the origin) was not significantly different from $1(P=0.2985, F$ test, REG procedure, SAS $)$, indicating a consistent trend in observed and predicted values. Examination of diagnostic residual plots indicated the presence of four outliers, two high-leverage points, and one high-leverage point that was also an outlier. Because of the small number of high-leverage points, individual estimated parameters were not greatly influenced by extreme values. Residuals plotted against predicted values exhibited a random scatter. The developed model predicted the general trend in observed spore density moderately well (Figs. 4 and 5 ), but based on the pseudo- $R^{2}$ and $\rho_{C}$, predictions could be considerably better.

\section{Discussion}

The results of this research add to our knowledge of the epidemiology of Phomopsis cane and leaf spot on grapevine, espe- cially in terms of the sporulation by the fungus for this simple interest $(3,28)$ disease. Before these studies, the relationship among temperature, wetness duration, IWD, and sporulation of $P$. viticola on infected grape canes was not quantified or not known. Sporulation was highest between 18 and $25^{\circ} \mathrm{C}$ after at least $47 \mathrm{~h}$ wetness duration. At least $50 \%$ of the maximum predicted sporulation during constant environmental conditions occurred between approximately 17 and $28^{\circ} \mathrm{C}$ after at least $47 \mathrm{~h}$ wetness duration. Conversely, sporulation was lowest when temperature was less than $10^{\circ} \mathrm{C}$, greater than $30^{\circ} \mathrm{C}$, or at wetness durations less than $12 \mathrm{~h}$ Environmental conditions determined to be favorable for sporulation of $P$. viticola in these studies were similar to conditions favorable for $P$. viticola to infect grape shoots and leaves $(12,31)$. However, there were some clear, if small, differences in conditions necessary for infection and sporulation. Optimum sporulation was predicted to occur at $\sim 21^{\circ} \mathrm{C}$, which is approximately $3^{\circ} \mathrm{C}$ warmer than the optimum reported for $P$. viticola to infect Catawba leaves and shoots, and it is 1 and $5^{\circ} \mathrm{C}$ warmer than the optimum for infection of 'Seyval' leaves and shoots, respectively (12). In general, if conditions are suitable for sporulation to occur, it is likely that infection would also occur shortly thereafter, provided there is sufficient wetness duration and that temperature does not change drastically. Of course, specific amounts of sporulation and subsequent infection would depend on actual values of temperature and wetness duration. The optimum temperature range for sporulation of $P$. viticola in this study is very close to the optimal range for sporulation of Plasmopara viticola (Berk. \& Curt.) Berl. \& de Toni, (18 to $\left.22^{\circ} \mathrm{C}\right)(17)$, causal agent of grape downy mildew, and Botrytis cinerea Perf.:Fr., (15 to $\left.25^{\circ} \mathrm{C}\right)(7)$, causal agent of Botrytis bunch rot on grape. In comparison to another Phomopsis spp., $P$. amygdali (Del.) Tuset \& Portilla, the optimum temperatures of sporulation were very similar $\left(21^{\circ} \mathrm{C}\right.$ for $P$. viticola compared to 22 to $23^{\circ} \mathrm{C}$ for $P$. amygdali) (25).

Table 3. Correlation of parameter estimates of the generalized Beta (equation 4), polynomial (equation 2), and generalized Weibull (equation 3) models fitted to the data from the controlled environment study for temperature and wetness duration effects on sporulation of Phomopsis viticola on grapes

\begin{tabular}{|c|c|c|c|c|c|c|c|c|}
\hline Model & & & & & & & & \\
\hline Beta & $\begin{array}{l}\alpha \\
\gamma \\
\beta \\
\delta\end{array}$ & \begin{tabular}{c}
\multicolumn{1}{c}{$\alpha$} \\
1 \\
0.759 \\
0.745 \\
-0.466
\end{tabular} & \begin{tabular}{l}
\multicolumn{1}{c}{$\gamma$} \\
0.759 \\
1 \\
0.957 \\
0.205
\end{tabular} & \begin{tabular}{l}
\multicolumn{1}{c}{$\beta$} \\
0.745 \\
0.957 \\
1 \\
0.223
\end{tabular} & \begin{tabular}{c}
\multicolumn{1}{c}{$\delta$} \\
-0.466 \\
0.205 \\
0.223 \\
1
\end{tabular} & & & \\
\hline EVP Beta ${ }^{a}$ & $\begin{array}{l}S_{1} \\
S_{2} \\
\beta \\
\delta\end{array}$ & \begin{tabular}{c}
\multicolumn{1}{c}{$S_{1}$} \\
1 \\
0.430 \\
-0.049 \\
-0.793
\end{tabular} & $\begin{array}{c}S_{2} \\
0.430 \\
1 \\
-0.871 \\
-0.416\end{array}$ & \begin{tabular}{c}
\multicolumn{1}{c}{$\beta$} \\
-0.049 \\
-0.871 \\
1 \\
0.223
\end{tabular} & $\begin{array}{c}\delta \\
-0.793 \\
-0.416 \\
0.223 \\
1\end{array}$ & & & \\
\hline Polynomial & $\begin{array}{l}b_{1} \\
b_{2} \\
b_{3}\end{array}$ & \begin{tabular}{r}
\multicolumn{1}{c}{$b_{1}$} \\
1 \\
-0.874 \\
0.779
\end{tabular} & $\begin{array}{c}b_{2} \\
-0.874 \\
1 \\
-0.969\end{array}$ & $\begin{array}{c}b_{3} \\
0.779 \\
-0.969 \\
1\end{array}$ & & & & \\
\hline Weibull & $\begin{array}{l}\psi \\
\xi \\
\varsigma \\
\varphi \\
\zeta \\
\eta \\
\theta\end{array}$ & \begin{tabular}{c}
$\psi$ \\
\multicolumn{1}{c}{1} \\
0.019 \\
0.967 \\
0.427 \\
-0.018 \\
-0.016 \\
-0.012
\end{tabular} & \begin{tabular}{c}
\multicolumn{1}{c}{} \\
0.019 \\
1 \\
0.022 \\
-0.007 \\
0.559 \\
0.707 \\
-0.827
\end{tabular} & $\begin{array}{c}\varsigma \\
0.967 \\
0.022 \\
1 \\
0.358 \\
-0.032 \\
-0.028 \\
0.019\end{array}$ & $\begin{array}{c}\varphi \\
0.427 \\
-0.007 \\
0.358 \\
1 \\
0.219 \\
0.205 \\
-0.100\end{array}$ & $\begin{array}{c}\zeta \\
-0.018 \\
0.559 \\
-0.032 \\
0.219 \\
1 \\
0.976 \\
-0.914\end{array}$ & \begin{tabular}{c}
\multicolumn{1}{c}{$\eta$} \\
-0.016 \\
0.707 \\
-0.028 \\
0.205 \\
0.976 \\
1 \\
-0.972
\end{tabular} & $\begin{array}{c}\theta \\
-0.012 \\
-0.827 \\
0.019 \\
-0.100 \\
-0.914 \\
-0.972 \\
1\end{array}$ \\
\hline
\end{tabular}

${ }^{a}$ Expected-value parameterization of the Analytis Beta model (equation A4).

Table 4. Parameter estimates of the expected value parameterization of the Analytis Beta model fitted to the data from the controlled environment study for temperature and wetness duration effects on sporulation of Phomopsis viticola on grapes ${ }^{\mathrm{a}}$

\begin{tabular}{|c|c|c|c|c|c|}
\hline$S_{1}$ & $S_{2}$ & $\boldsymbol{\beta}$ & $\delta$ & $s_{e}^{2}$ & $s_{r}^{2}$ \\
\hline $0.967(0.078)$ & $0.569(0.095)$ & $2.353(0.429)$ & $1.033(0.099)$ & $0.104(0.013)$ & $0.081(0.068)$ \\
\hline
\end{tabular}


It was not surprising that among the examined models for sporulation (polynomial, generalized Weibull, and Analytis Beta), the best fitting model was nonlinear. While fitting nonlinear models generally involves more effort than linear models, the accompanying increased biological meaning $(8,15,26)$ and superiority in accounting for asymptotic (limiting) behavior $(42,46)$ makes nonlinear models valuable choices when quantitatively describing biological phenomena. At best, linear (e.g., polynomial) models can only approximate asymptotic behavior. When predictions are made outside the range of values used to fit a polynomial model, nonsensical predictions can be obtained (43) (e.g., negative values when the response variable can only take on positive values). Even if interest is only in predictions within the observed range of values, resulting polynomial parameter estimates often cannot be interpreted biologically $(4,43)$. Several nonlinear models have been developed for biological responses to temperature (37), and some have been expanded to include the effect of wetness duration or time period (e.g., von Bertalanffy-Richards and Weibull models) $(8,24,34,40,48)$. However, many of those models may be overparameterized or possess high levels of parameter-effects nonlinearity, such as the von Bertalanffy-Richards model $(36,37,40,48)$, some of the original parameterizations of the logistic and Gompertz models $(37,38)$, and Sharpe and DeMichele's thermodynamic model $(37,45)$. While all possible models capable of describing sporulation as a function of temperature and wetness duration were clearly not investigated in the current study, the examined models were capable of capturing the general trends we would expect to see in this relationship (i.e., monotonic increase of sporulation with increasing wetness duration to an upper limit and an increase in sporulation from minimum and maximum temperatures toward a central optimum temperature). In the present study, expected-value parameterizations were incorporated into the nonlinear modeling, as recommended by Ratkowsky (37) and Schabenberger and Pierce (42), in order to improve estimation behavior and parameter-estimate properties. Use of expected-value parameterizations in other disciplines has been reported recently $(16,35,47)$; however, within plant pathology such methods appear to be rare or nonexistent.

Multiple factors are involved with the magnitude of sporulation and subsequent splash dispersal per LWE in the field. We developed one protocol for characterizing spore densities over time in relation to temperature and wetness duration effects on spore production by adjusting for some of the other factors that are likely contributing to the density of trapped spores. The temporal trend of (predicted and observed) spore density, rather than its magnitude at

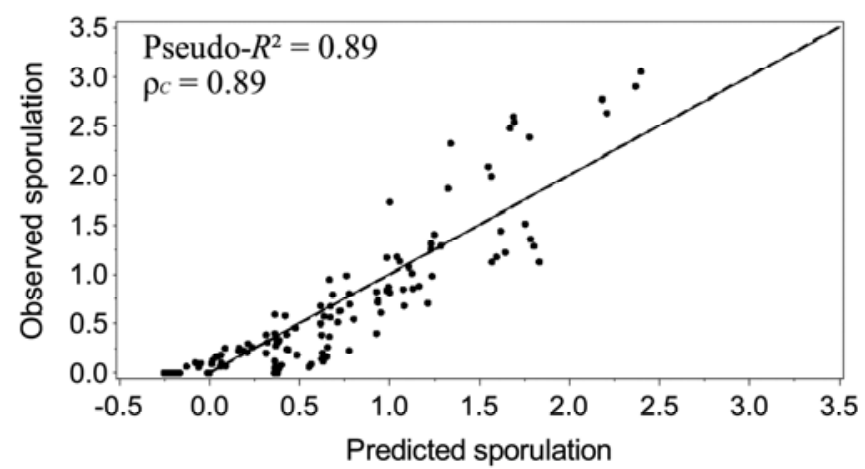

Fig. 2. Plot of observed and predicted sporulation of Phomopsis viticola on infected 'Catawba' canes in 2009, 2010, and 2011. Predictions were determined by fitting equation 1 (with equation 4 for $f(T, W)$ to the sporulation data from the controlled environment study (the first objective). Regression was performed using the NLMIXED procedure (SAS 9.2, Cary, NC) incorporating year as a random effect. The dashed line represents the regression line, whereas the solid line represents the concordance line (line of perfect agreement; slope of 1 and intercept of 0 ). Pseudo- $R^{2}$ is an indication of the variability explained by the model (upper limit of 1). $\rho_{c}$ is a measure of reliability between predictions and observations that ranges from -1 to 1 , where a value of 1 indicates perfect reliability (slope of 1 and intercept of 0 ) and 0 indicates a random scatter (negative values would indicate that predicted values decrease as observed values increase). a given time, was emphasized here based on the analytical results, as the magnitude of predicted and observed spore density will be affected by biotic and environmental factors that can change during the season and are spatially variable at any given time. Clearly, not all possible factors were considered in this study, or the considered factors were reduced to a single parameter. For instance, rainsplash dispersal is a complex process $(13,14,21,33)$, and we reduced the rainfall effects to one parameter $(V)$ because this study was not designed to characterize rain-splash, per se. One factor not addressed was how the growing canopy of the grapevines over the course of the sampling period likely affected the amount of actual rainfall that came into contact with produced inoculum on infected tissues, or how the canopy affected the transport of spores. This was a confounding factor in estimating the dispersal index, since the rain gauge was positioned next to the vineyard and not within the canopy. Actual dispersal would be expected to be inversely proportional to amount of canopy cover. Thus, the estimated dispersal index reflects more than just the direct rainfall effect. If canopy cover information was available, a more complex $D$ function could be defined to account for rain and canopy. Nevertheless, despite the simplifications used in our investigation, results show that the model developed under controlled conditions can predict the temporal trend in spore density in the vineyard moderately well. With a few exceptions, the temporal pattern to predicted
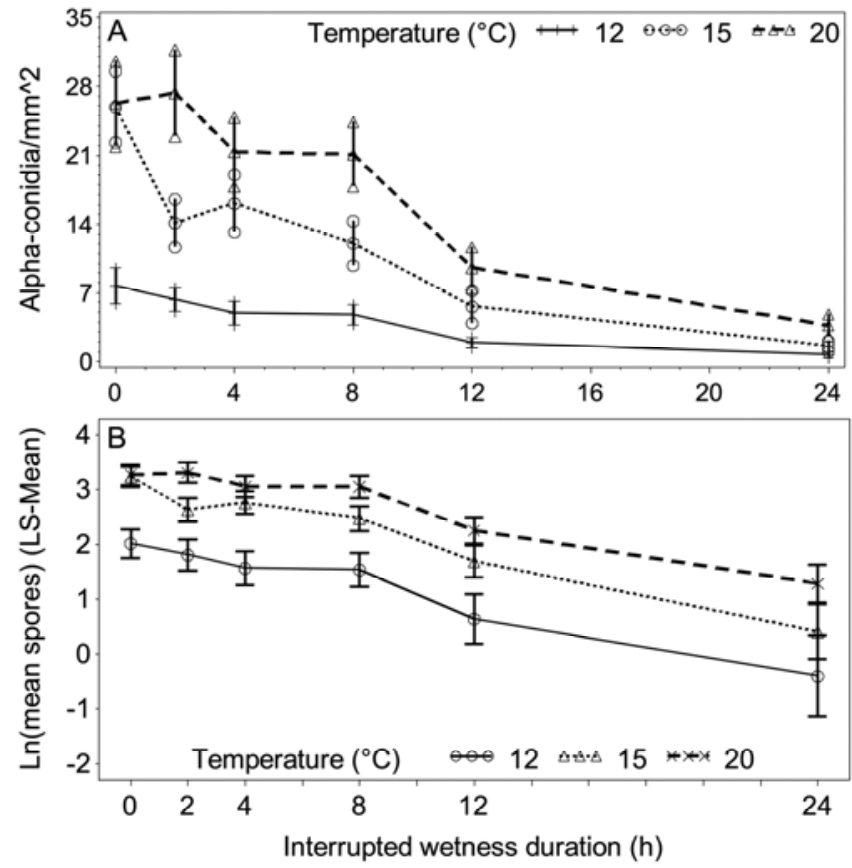

Fig. 3. A, Effect of interrupted wetness duration on the sporulation rate of Phomopsis viticola on infected grape canes. Error bars are standard errors of the mean of two repetitions. B, Interaction plot of least squares means (log link scale) versus interrupted wetness duration. Error bars are standard errors about the least squares mean of two repetitions.

Table 5. Contrasts of least squares means (log link scale) of Phomopsis viticola sporulation at different interrupted wetness durations

\begin{tabular}{lcr}
\hline Contrast $^{\mathbf{a}}$ & Estimated difference $^{\mathbf{b}}$ & \multicolumn{1}{c}{$\boldsymbol{P}^{\mathbf{c}}$} \\
\hline 0 vs. 2 & $0.259(0.137)$ & 0.1297 \\
0 vs. 4 & $0.377(0.143)$ & 0.0285 \\
0 vs. 8 & $0.487(0.147)$ & 0.0056 \\
0 vs. 12 & $1.311(0.200)$ & $<0.0001$ \\
0 vs. 20 & $2.410(0.321)$ & $<0.0001$ \\
\hline
\end{tabular}

a Values are hours of interrupted wetness duration.

${ }^{b}$ Values are estimates of differences (estimated standard errors) of treatment least squares means with the control (one-sided test, PROC GLIMMIX).

${ }^{c}$ Adjusted for multiple comparisons via Monte Carlo simulation $(\alpha=0.01)$. 
spore density was consistent with the pattern of the observed trapped spores.

In an earlier publication, Anco et al. found that predicted relative sporulation potential of $P$. viticola was greater than $50 \%$ from 28 April to 3 June (3). Here we found that the majority (72.8\%) of spore density observed in the vineyard over all years in the current study occurred during this same timeframe, although there was considerable variation in actual sporulation from rain-to-rain during this period. However, the highest observed spore density in 2010 occurred on 6 June, which was 3 days after this timeframe. This observation of high sporulation after the high-risk period, coupled with the variation among observed spore densities, rein-
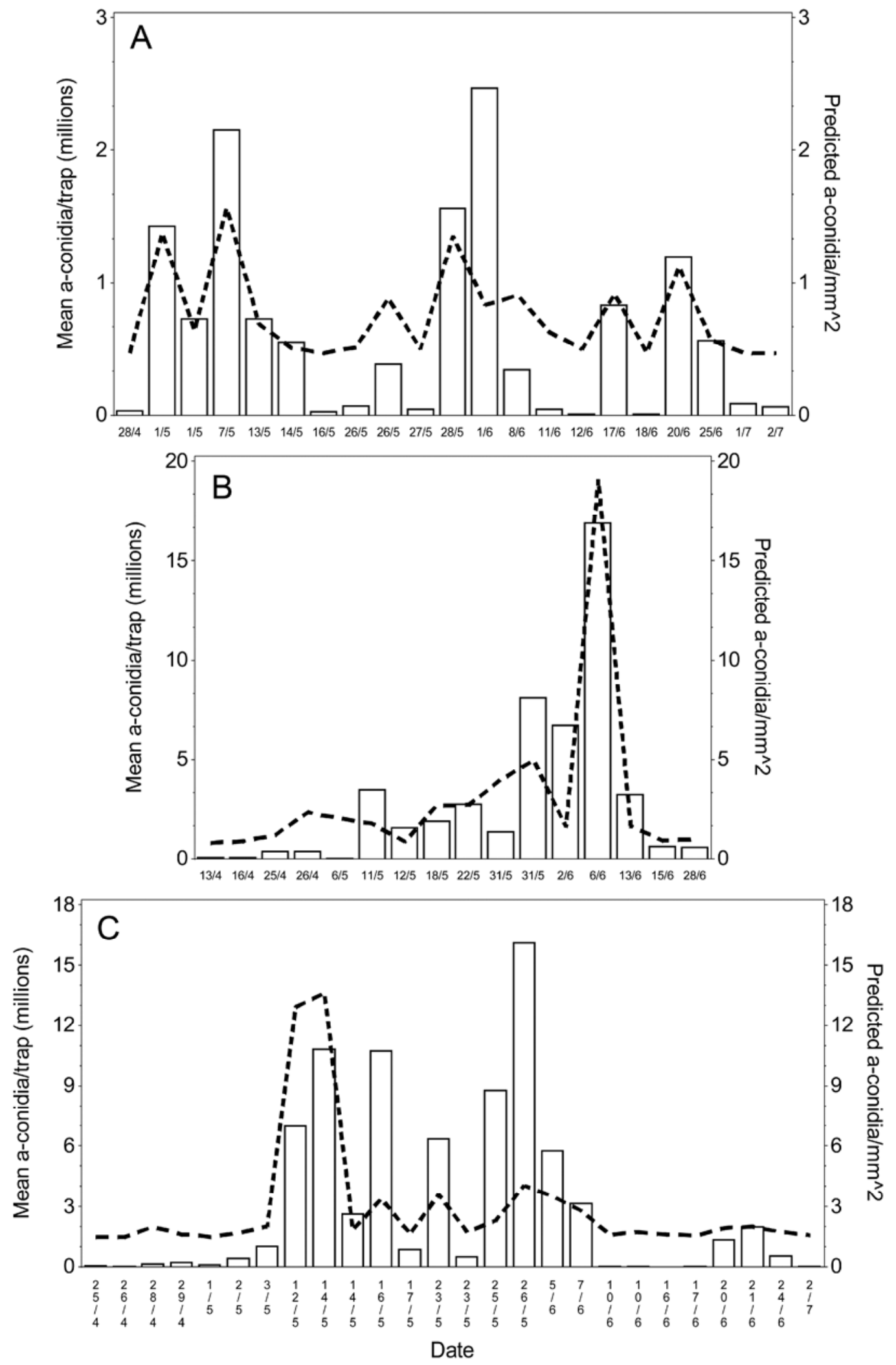

Fig. 4. Predicted and observed spore density in a 'Catawba' vineyard in A, 2009, B, 2010, and C, 2011. Bars represent mean a-conidia per rain-splash trap observed per rain event. Dates correspond to rain event ending dates. The plotted line represents sporulation $/ \mathrm{mm}^{2}$ infected cane tissue predicted by equation 5 , which is based on the use of equation 4 for predicted sporulation at constant temperature and wetness conditions, coupled with a dispersal function (based on rain amount), and a time-of-the-year weight. 
forces the importance of environmental factors (such as those investigated in the current study) in predicting levels of sporulation of $P$. viticola in the vineyard.

The trend of higher predicted than observed spore density for periods in 2010 (from 26 April to 6 May, and around 31 May), and lower predictions than observations around 26 May 2011, likely is a function of multiple factors. In addition to the possible oversimplification of both the dispersal index (described above) and the time-of-season weight $\left(w_{d}\right)$, the sequence and number of wetness events associated with the rain episodes may have contributed to the discrepancy. For most of the rain events in these periods of discrepancy in 2010, for instance, there were multiple days since the last rain event. This corresponded to an increased number of LWEs resulting just from dew before the rain. While those LWEs individually amounted to little predicted sporulation (D. J. Anco, unpublished), the accumulation of predicted sporulation from many such LWEs may have contributed to the relatively high magnitudes of total predicted spore density for the rain events that subsequently occurred. These discrepancies between observed and predicted spore density may be remediated by incorporating an inoculum mortality index, perhaps based on the effects of solar or ultraviolet radiation $(22,23,41)$ and relative humidity $(5,50)$ on $P$. viticola $\alpha$-conidia survival. Future studies will have to determine these effects on the conidia density. These future studies will explore other environmental factors that are associated with the largest residuals from the fit of equation 5 to the data. The model in equation 5 could then be improved through modifications of the last term on the right hand side. Among other things, modifications could be made to include sporulation and dispersal from more than the current and previous rain events, and by incorporating a mortality or spore-loss parameter.

The absence of observed spore density in the vineyard in 2010 and 2011 prior to bud break, despite the presence of environmental conditions favorable for sporulation, suggests that additional factors are involved in determining when pycnidia of $P$. viticola first sporulate $(2,3)$. Although not investigated in this study, it is possible that $P$. viticola responds to physiologic changes of the grapevine as the plant breaks dormancy. Alternatively, it is possible that $P$. viticola has a temperature degree-day requirement for initial sporulation, separate from the requirement of certain combinations of temperature and wetness duration investigated here for sporulation rate. The present studies were not designed to determine such a degree-day requirement of $P$. viticola; however, in 2010, greater degree-day values accompanied an earlier first date of observed spore density than in 2011 (13 April 2010 compared to 25 April 2011; data not shown), based on daily averages with a base temperature of $10^{\circ} \mathrm{C}$. Interestingly, Anco et al. (3) found that potential sporulation could be more accurately predicted by day of year than by degree days. Regardless, the current observations suggest that primary inoculum of $P$. viticola is produced (and disseminated) during an extensive time period early in the growing season when grape tissue is susceptible, and that environmental conditions favor high levels of sporulation during portions of this time period. Observations from these studies also confirm the importance of controlling this disease with fungicides during the early part of the growing season $(6,31,32$; W. F. Wilcox, personal communication).

Increasing our knowledge of the epidemiology of PCLS will hopefully allow us to develop more effective disease management programs for this disease. Erincik et al. developed a predictive model for infection of grape shoots and leaves by $P$. viticola based on the environmental variables of temperature and leaf wetness (12). Nita et al. incorporated the model into a disease warning (forecasting) system and validated the system in the field (31). The warning system was shown to be useful in reducing the overall number of fungicide applications while providing about the same level of control as a calendar-based protectant program (31). The use of disease forecasting to schedule fungicide applications is an attractive alternative to the standard calendar-based protectant program that applies fungicide every 7 to 10 days regardless of whether or not high-risk periods have occurred for the disease. In dry growing seasons, applying fungicides in response to predicted infection periods should result in improved timing of fungicide application and a reduction in overall fungicide use. This approach to disease management complements the current philosophy and use of integrated pest management programs. One weakness of the warning system is that it does not take the presence, production, and dispersal of primary inoculum into account. Obviously, unless the proper conditions for sporulation (and dispersal) have been met prior to the infection event, there can be no infection. Moreover, for a given risk of infection, the number of infections will be proportional to the level of spore production (up to a saturation level). The predictive model for sporulation of $P$. viticola developed in these studies will ultimately be incorporated into Nita's warning system, further increasing its generality in scheduling fungicide applications. This increased generality could improve our ability to control this disease, which could also result in increased profitability to U.S. grape producers and a potential reduction in overall fungicide use and deposition in the environment.

\section{Appendix 1}

Expected-value reparameterization of the generalized Analytis Beta model. As described by Ratkowsky (37) and Schabenberger and Pierce (42), re-expression of $f(T, W)$ in an equivalent mathematical form (reparameterization) can, in general, result in more linear-model-like behavior of the parameter estimates (more specifically, less parameter-effects nonlinearity), which is translated into lower asymptotic standard error and bias, skewness, and correlation of the estimates. Consequently, reparameterization often leads to rapid convergence of the iterative model-fitting algorithm. Parameter-effects nonlinearity can be assessed via simulation studies (36) or by calculating Hougaard's skewness $(20,37)$. Parameters that display apparent skewness (i.e., |Hougaard's skewness $\mid>0.25$ ) could be considered for reparameterization, and those with considerable nonlinear behavior (|Hougaard's skewness $\mid>1$ ) should seriously be considered for reparameterization (37). Reparameterization of parameters was based on the magnitude of Hougaard's skewness and whether or not expected-value reparameterization was possible (i.e., not all parameters can be replaced with expected-value parameterizations [37]). Another benefit of expected-value parameterizations is how they provide obvious starting values for the reparameterized parameters with which to initiate the iterative algorithm $(37,42)$.

From the original parameterization of equation 4 , and when $T_{\min }$ and $T_{\max }$ were, respectively, assumed to be 4 and $36^{\circ} \mathrm{C}$, a new parameterization was utilized to improve model fitting and to obtain estimated parameters with more desirable statistics properties (37).

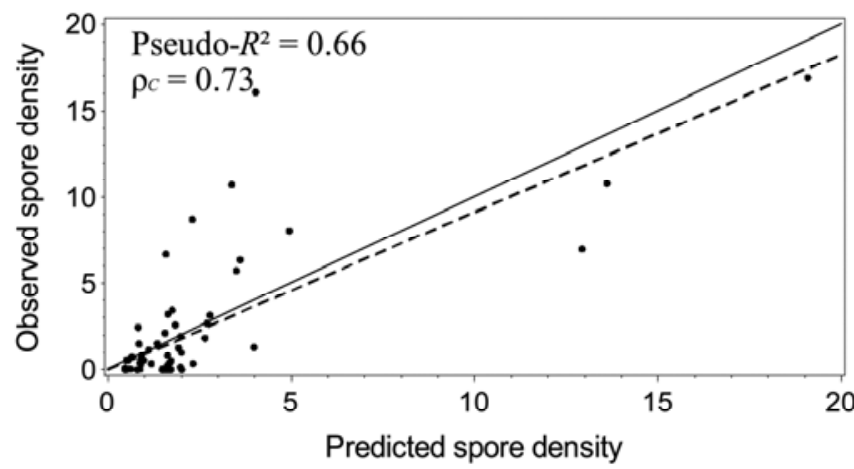

Fig. 5. Plot of observed and predicted spore density for the 'Catawba' vineyard in 2009, 2010, and 2011. Regression was performed using the NLMIXED procedure (SAS 9.2, Cary, NC) incorporating year as a random effect. The dashed line represents the regression line, whereas the solid line represents the concordance line (line of perfect agreement; slope of 1 and intercept of 0 ). Pseudo- $R^{2}$ is an indication of the variability explained by the model (upper limit of 1 ). $\rho_{C}$ is a measure of reliability between predictions and observations that ranges from -1 to 1 , where a value of 1 indicates perfect reliability (slope of 1 and intercept of 0 ) and 0 indicates a random scatter (negative values would indicate that predicted values decrease as observed values increase) 
$\alpha$ and $\gamma$ were re-expressed using the expected-value parameterization. The approach involves choosing values of the predictor variables ( $T$ and $W$ ) with observed $y$ values, and defining parameters for the expected values of $y(E(y))$ at these levels of the predictor variables. We first define $S_{1}$ (the first expected value parameter) as $E(y)$ for $T=20^{\circ} \mathrm{C}$ and $W=35 \mathrm{~h}$. Substituting $S_{1}$ for the left-hand side of equation 4 , and rearranging, $\alpha$ can be solved as

$a=\frac{S_{1} 2^{\beta+\gamma}}{35^{\delta}}$

Substituting this expected-value parameterization for $\alpha$ in equation 4 yields

$f(T, W)=\left(\frac{S_{1} 2^{[\beta+\gamma]}}{35^{\delta}}\right) t^{\beta}(1-t)^{\gamma} W^{\delta}$

We then define $S_{2}$ (the second expected value parameter) as $E(y)$ for $T=12^{\circ} \mathrm{C}$ and $W=47 \mathrm{~h}$. Substituting $S_{2}$ for the left-hand side of equation $\mathrm{A} 2$, rearranging and solving for $\gamma$, yields

$\gamma=\frac{\delta \ln \frac{35}{47}+\beta \ln 2+\ln \frac{S_{2}}{S_{1}}}{\ln \frac{3}{2}}$

Substituting equation A3 for $\gamma$ in equation A2 then gives an expected-value parameterization of the generalized Analytis Beta model, where two parameters have been replaced by expectedvalue ones:

$f(T, W)=\left(\frac{S_{1}}{35^{\delta}} 2^{[\beta+\kappa]}\right) t^{\beta}(1-t)^{\kappa} W^{\delta}$

where

$\kappa=\left[\delta \ln \frac{35}{47}+\beta \ln 2+\ln \frac{S_{2}}{S_{1}}\right] \div \ln \left(\frac{3}{2}\right)$

Starting values for $S_{1}$ and $S_{2}$ (to be used in the iterative modelfitting algorithm) are the average levels of sporulation observed at the chosen predictor values of $T$ and $W$. Once equation A4 is fitted to data, substituting the resulting parameter-estimates into equations $\mathrm{A} 1$ and $\mathrm{A} 3$ would provide estimates of $\alpha$ and $\gamma$, respectively.

\section{Acknowledgments}

Salaries and research support were provided by state and federal funds to the Ohio Agricultural Research and Development Center. Funding was also provided by the USDA-CREES Viticulture Consortium-East Research Grants Program and The Ohio Grape Industries Program. We thank L. L. Wilson for his contributions.

\section{Literature Cited}

1. Analytis, S. 1977. Über die relation zwischen biologischer entwicklung und temperatur bei phytopathogenen pilzen. Phytopathol. Z. 90:64-76.

2. Anco, D. J., Madden, L. V., and Ellis, M. A. 2012. Effects of temperature and wetness duration on the sporulation of Phomopsis viticola on infected grape canes. Online. Plant Health Progress doi: 10.1094/PHP-RS-12-0025.

3. Anco, D. J., Madden, L. V., and Ellis, M. A. 2012. Temporal patterns of sporulation potential of Phomopsis viticola on infected grape shoots, canes, and rachises. Plant Dis. 96:1297-1302.

4. Arauz, L. F., Neufeld, K. N., Lloyd, A. L., and Ojiambo, P. S. 2010. Quantitative models for germination and infection of Pseudoperonospora cubensis in relation to temperature and duration of leaf wetness. Phytopathology 100:959-967.

5. Bashi, E., and Aylor, D. E. 1983. Survival of detached sporangia of Peronospora destructor and Peronospora tabacina. Phytopathology 73:1135-1139.

6. Bordelon, B., Ellis, M. A., and Welty, C. 2011. Midwest Small Fruit and Grape Spray Guide. Ohio State University Ext. 506B2.

7. Dami, I., Bordelon, B., Ferree, D. C., Brown, M., Ellis, M. A., Williams, R. N., and Doohan, D. 2005. Midwest Grape Production Guide. Ohio State University Ext. Bull. 919.

8. Duthie, J. 1997. Models of the response of foliar parasites to the combined effects of temperature and duration of wetness. Phytopathology 87:10881095.

9. Edwards, D., and Berry, J. J. 1987. The efficiency of simulation-based multiple comparisons. Biometrics 43:913-928.

10. Eichhorn, K. W., and Lorenz, D. H. 1977. Phänologische Entwicklungsstadien der Rebe. Nachrichtenbl. Dtsch. Pflanzenschutzdienstes (Braun- schweig) 29:119-120

11. Erincik, O., Madden, L. V., Ferree, D. C., and Ellis, M. A. 2001. Effect of growth stage on susceptibility of grape berry and rachis tissues to infection by Phomopsis viticola. Plant Dis. 85:517-520.

12. Erincik, O., Madden, L. V., Ferree, D. C., and Ellis, M. A. 2003. Temperature and wetness duration requirements for grape leaf and cane infection by Phomopsis viticola. Plant Dis. 87:832-840.

13. Fitt, B. D. L., and McCartney, H. A. 1986. Spore dispersal in splash droplets. In: Water, Fungi, and Plants. P. G. Ayres and L. Boddy, eds. Cambridge University Press, New York.

14. Fitt, B. D. L., McCartney, H. A., and Walklate, P. J. 1989. The role of rain in dispersal of pathogen inoculum. Annu. Rev. Phytopathol. 27:241-270.

15. Gilligan, C. A. 1990. Comparison of disease progress curves. New Phytol. 115:223-242.

16. Hall, D. B., and Clutter, M. 2004. Multivariate multilevel nonlinear mixed effects models for timber yield predictions. Biometrics 60:16-24.

17. Hewitt, W. B., and Pearson, R. C. 1988. In: Compendium of Grape Diseases. R. C. Pearson and A. Goheen, eds. American Phytopathological Society, St. Paul, MN

18. Hirotsu, C., and Srivastava, M. S. 2000. Simultaneous confidence intervals based on one-sided max $t$ test. Stat. Probability Lett. 49:25-37.

19. Hougaard, P. 1982. Parametrizations of non-linear models. J. Roy. Stat. Soc. 44:244-252.

20. Hougaard, P. 1985. The appropriateness of the asymptotic distribution in a nonlinear regression model in relation to curvature. J. Roy. Stat. Soc. 47:103-114.

21. Huber, L., Madden, L. V., and Fitt, B. D. L. 2006. Environmental biophysics applied to the dispersal of fungal spores by rain-splash. In: The Epidemiology of Plant Diseases, 2nd ed. B. M. Cooke, D. Gareth Jones, and B. Kaye, eds. Springer, Dordrecht, The Netherlands.

22. Isard, S. A., Dufault, N. S., Miles, M. R., Hartman, G. L., Russo, J. M., De Wolf, E. D., and Morel, W. 2006. The effect of solar irradiance on the mortality of Phakopsora pachyrhizi urediniospores. Plant Dis. 90:941-945.

23. Kanetis, L., Holmes, G. J., and Ojiambo, P. S. 2010. Survival of Pseudoper onospora cubensis sporangia exposed to solar radiation. Plant Pathol. 59:313-323.

24. Lalancette, N., Ellis, M. A., and Madden, L. V. 1988. Development of an infection efficiency model for Plasmopara viticola on American grape based on temperature and duration of leaf wetness. Phytopathology 78:794800.

25. Lalancette, N., Foster, K. A., and Robison, D. M. 2003. Quantitative models for describing temperature and moisture effects on sporulation of Phomopsis amygdale on peach. Phytopathology 93:1165-1172.

26. Li, B.-H., Xu, X.-M., Li, J.-T., and Li, B.-D. 2005. Effects of temperature and continuous and interrupted wetness on the infection of pear leaves by conidia of Venturia nashicola. Plant Pathol. 54:357-363.

27. Lin, L. I.-K. 1989. A concordance correlation coefficient to evaluate reproducibility. Biometrics 45:255-268.

28. Madden, L. V., Hughes, G., and van den Bosch, F. 2007. The Study of Plant Disease Epidemics. American Phytopathological Society, St. Paul, $\mathrm{MN}$

29. Nita, M., Ellis, M. A., and Madden, L. V. 2008. Variation in disease incidence of Phomopsis cane and leaf spot in commercial vineyards in Ohio. Plant Dis. 92:1053-1061.

30. Nita, M., Ellis, M. A., and Madden, L. V. 2012. Spatial pattern of Phomopsis cane and leaf spot symptoms in commercial vineyards in Ohio. J. Phytopathol. 160:26-36.

31. Nita, M., Ellis, M. A., Wilson, L. L., and Madden, L. V. 2006. Evaluation of a disease warning system for Phomopsis cane and leaf spot of grape: A field study. Plant Dis. 90:1239-1246.

32. Nita, M., Ellis, M. A., Wilson, L. L., and Madden, L. V. 2007. Evaluations of new and current management strategies to control Phomopsis cane and leaf spot of grape. Online. Plant Health Progress doi: 10.1094/PHP-20070726-06-RS.

33. Ntahimpera, N., Madden, L. V., and Wilson, L. L. 1997. Effect of rain distribution alteration on splash dispersal of Colletotrichum acutatum. Phytopathology 87:649-655.

34. Pennypacker, S. P., Knoble, H. D., Antle, C. E., and Madden, L. V. 1980. A flexible model for studying plant disease progression. Phytopathology 70:232-235.

35. Portner, H., Bugmann, H., and Wolf, A. 2010. Temperature response functions introduce high uncertainty in modeled carbon stocks in cold temperature regimes. Biogeosciences 7:3669-3684.

36. Ratkowsky, D. A. 1983. Nonlinear Regression Modeling: A Unified Practical Approach. Marcel Dekker, New York.

37. Ratkowsky, D. A. 1990. Handbook of Nonlinear Regression Models. Marcel Dekker, New York.

38. Ratkowsky, D. A. 1993. Principles of nonlinear regression modeling. J. Industrial Microbiol. 12:195-199.

39. Reynolds, K. M., Madden, L. V., and Ellis, M. A. 1988. Effect of weather variables on strawberry leather rot epidemics. Phytopathology 78:822827.

40. Richards, F. J. 1959. A flexible growth function for empirical use. J. Exp Bot. 10:290-300. 
41. Rotem, J., Wooding, B., and Aylor, D. E. 1985. The role of solar radiation, especially, ultraviolet, in the mortality of fungal spores. Phytopathology 75:510-514.

42. Schabenberger, O., and Pierce, F. J. 2002. Contemporary Statistical Models for the Plant and Soil Sciences. CRC Press, Boca Raton, FL.

43. Scherm, H., and van Bruggen, A. H. C. 1993. Response surface models for germination and infection of Bremia lactucae, the fungus causing downing mildew of lettuce. Ecol. Modelling 65:281-296.

44. Schilder, A. M. C., Erincik, O., Castlebury, L., Rossman, A., and Ellis, M. A. 2005. Characterization of Phomopsis spp. infecting grapevines in the Great Lakes region of North America. Plant Dis. 89:755-762.

45. Sharpe, P. J. H., and DeMichele, D. W. 1977. Reaction kinetics of poikilo- therm development. J. Theor. Biol. 64:649-670.

46. Stevens, W. L. 1951. Asymptotic regression. Biometrics 7:247-267.

47. Stewart, B., Jordan, L., and Rongxia, L. 2011. Comparing traditional longitudinal modeling strategies of forestry with mixed-effects models: Restrictions in model formulation. For. Sci. 57(5):408-415.

48. von Bertalanffy, L. 1941. Stoffwechseltypen und wachstumstypen. Biol. Zentralbl. 61:510-532.

49. Weibull, W., and Sweden, S. 1951. A statistical distribution function of wide applicability. J. Appl. Mech. 18:293-297.

50. Xu, X.-M., Butt, D. J., and Van Santen, G. 1995. A dynamic model simulating infection of apple leaves by Venturia inaequalis. Plant Pathol. 44:865 876. 